\title{
Boundaries, Expectations and Empirical Research: A Commentary on Judith Becker's "Crossing Boundaries"
}

\author{
ERIC CLARKE \\ Faculty of Music, University of Oxford
}

\begin{abstract}
In her paper "Crossing Boundaries", Judith Becker raises and discusses important points about where various boundaries between different ways of studying music might lie, how we negotiate those boundaries, and some of the frustrations that ensue in trying to get boundary-crossing work published. This response considers the increasingly heterogeneous nature of musicology itself; some possible overlaps, discontinuities and confusions between the terms 'psychological', 'empirical' and 'scientific'; and the different institutional expectations and reviewing styles that often apply to work in the humanities and the sciences. There is no doubt that these differences can cause problems, conflicts, and misunderstandings; but my response ends by recognising the vigorous health of current interdisciplinary research in music, and the opportunities for carrying out and disseminating 'boundary-crossing' research that now present themselves, of which this journal Empirical Musicology Review - is one.
\end{abstract}

Submitted 2009 April 21; accepted 2009 May 20.

KEYWORDS: Empirical, scientific, musicology, psychology, humanities

IT has become a bit of a truism that the study and practice of music has become increasingly heterogeneous but in my response to Judith Becker's interesting and provocative "Crossing Boundaries: An Introductory Essay" I am going to start with that truism anyway. Taking note of cultural specificity in this respect, the term musicology in the UK embraces a wide variety of different perspectives - getting close, perhaps, to what the etymology of the term implies: 'words about music'. The first three sentences of the Grove entry for musicology read simply: "The term 'musicology' has been defined in many different ways. As a method, it is a form of scholarship characterized by the procedures of research. A simple definition in these terms would be 'the scholarly study of music'." (Duckles et al., 2009) And the Oxford English Dictionary entry for Musicology starts: "The branch of knowledge that deals with music as a subject of study rather than as a skill or performing art; academic research in or scholarly study of music. More generally: writing about music..." (OED). The purpose of the most recent research assessment exercise in the UK (RAE2008) was to assess research activity across all subjects in UK Higher Education. The opening statement on the research of music recognized "the rich diversity of research in music", and welcomed "all outputs arising from this research, in whatever genre or medium". It went on to declare that alongside composition, performance, new technology and music, and pedagogic research on music, it would recognize:

“• musicology (including historical, critical, empirical, ethnographic, theoretical, analytical and organological approaches)

- scientific approaches to the study of music

- musical acoustics and audio engineering" (RAE 01/2006 (O))

Despite the broad definition of musicology, which includes empirical and ethnographic approaches, 'scientific' approaches are nonetheless identified separately - and, weirdly, musical acoustics as separate from that! The apparent overlaps or redundancies between the bullet-points may be as much the reflection of an anxiety not to appear to exclude anything legitimate as a real confusion about what counts as 'scientific', and whether those elements are already within the broad sense of musicology. It is interesting, in the context of Judith Becker's concerns in this issue of Empirical Musicology Review, that neither ethnomusicology nor the psychology of music are specifically mentioned at all - presumably being subsumed within either 'musicology' or 'scientific approaches'. 
There is a limit to the value of dictionary definitions and panel declarations, since in the end what matters is how the institutions and individuals behave in practice. However, these various markers from the UK context do serve to indicate uncertainties about where the 'boundaries' lie, the crossing of which is Judith Becker's concern, if they are even there at all. Does the word 'empirical' necessarily imply 'scientific', for example? As David Huron pointed out 10 years ago in the third of his Ernest Bloch lectures (Huron, 1999), not at all: science is only one of a number of empirical approaches to knowledge, and quite a lot of standard humanities-based musicological methods are empirical (i.e. observation-based) in fairly obvious ways (looking at scores, listening to recordings, consulting treatises). Ethnomusicologists, of course, have been using empirical methods for decades, but as Becker's introductory essay makes clear, do not regard themselves as 'scientists' - and indeed may feel alienated from a scientific outlook.

A further complication is the relationship between science, empiricism and psychology specifically the psychology of music. It is all too easy for empirical musicology to become more or less synonymous with the psychology of music, and there is an element of this in Becker's introductory essay. The opening statement of the essay, referring back to the first issue of Empirical Musicology Review, has historical musicology and music theory on one side of a boundary, with the psychology of music on the other, implying that the psychology of music is the primary (or sole?) representative of an empirical and scientific approach. But that is not really the case in a number respects: first, not all psychology is empirical; second, arguably not all psychology is scientific; and third, the psychology of music is certainly not the only kind of empirical work in music. Becker is quite right to point out that other kinds of empirical approach were hardly represented in the first issue of Empirical Musicology Review, to which she refers at the start of her essay, but it would be unfortunate to allow the contents of that issue to define the field.

So, to bring this brief discussion of definitions and boundaries to a halt, I would argue: first, that there is a much more fluid relationship between scientific and humanities approaches implicit within the broad fields of musicology, ethnomusicology and the psychology of music than is sometimes suggested; second, that empirical musicology represents much more than the psychology of music, and that the psychology of music is not necessarily empirical.

Before I comment on Becker's case study and associated concerns, I will make some remarks about the intellectual as well as institutional basis for the kinds of response with which empirical approaches are sometimes met. For the last five years I have been a member of the UK Arts and Humanities Research Council funded Centre for the History and Analysis of Recorded Music (CHARM), and will be a member of the successor Centre for Musical Performance as Creative Practice (CMPCP) for the next five years. In CHARM (and this will be the case also for CMPCP) a group of researchers in a number of institutions, but in every case based in a music department, have carried out a wide-ranging research program on various aspects of the history and analysis of recorded music. Many of those projects, but not all, have used empirical methods; sometimes involving experiments with human participants, in other cases involving the collection of large bodies of quantitative performance data gathered from historical recordings. The results of this research have been met with both interest and enthusiasm and suspicion and hostility. Some of this comes from a genuine concern by humanities scholars that complex questions, embedded in historically and culturally rich circumstances, will necessarily be treated in a simplistic and reductionist manner if empirical methods are used. There is undoubtedly that risk, and there are, I am sure, examples of empirical investigation in the work of CHARM and elsewhere which could have addressed matters in more sophisticated or nuanced ways. But another factor is a kind of intellectual impatience: it often takes a significant amount of time to develop the empirical tools needed to tackle an issue systematically and sensitively, and 'early' results, in which the tools are being developed and tried out, may seem preliminary and obvious. The audience for this research needs to have the understanding to look ahead to what might be accomplished a little way down the road, and to be aware that different components of this kind of research cannot always be reported all together. The results of an apparently 'hard-nosed empirical approach in no way preclude a whole variety of complementary historical, analytical, and critical perspectives; in fact, quite the opposite. Where there is lack of understanding, furthermore, it is often significantly fuelled by resentment of the institutional kudos and financial support that empirical research is (sometimes) able to attract. Empirical research can involve the kind of equipment and employment of research assistants that brings in more conspicuous sums of money than conventional humanities scholarships. The consequent institutional 'grandstanding' of this research understandably generates resentment amongst other researchers who may be doing work that is just as valuable but which doesn't hit the funding headlines. In the context of a squeeze on arts and humanities funding (certainly in the UK), and an increasingly science-based model of research in general, this can be divisive amongst the various elements of music's otherwise vigorous interdisciplinarity. 
The specific case of Judith Becker and Joshua Penman's paper, and the concerns that are raised by their attempts to get it published in Psychology of Music, seems to turn around frustrations over the review process for the journal and a feeling that these arose from irreconcilable outlooks. Having been on the editorial or advisory boards for both more 'humanities' and more 'scientific' journals (h-journals and sjournals from hereon), it is my experience that there are different styles (and perhaps expectations) in the review process. Some s-journals, for example, publicize and take pride in their fierce selectivity (which may approach a 95\% rejection rate) in a manner that can be very off-putting to interdisciplinary scholars who want to publish their research in such outlets. And repeated requests for revision (third or even fourth requests for change before a paper will be accepted for publication) are not uncommon. The style of reviewer feedback may also differ significantly. In an s-journal it is quite standard to receive certainly two and often three separate reviews, together with the overall summary comments of an action editor or associate editor, who will not necessarily adjudicate between different (perhaps contradictory) comments and recommendations by the individual reviewers. Instead, it is usually left (in part) to the authors to disentangle, decided about, and then explain or defend in a covering letter that accompanies the revision. And the reviews themselves may be four or five pages long with detailed, line-by-line comments, specific requests for further information, additional analyses, or questions about particular methods and procedures. In many ways this is an extremely helpful and supportive review process, though it can be pretty challenging, and can at times seem frustrating: responding to what authors regard as a simple misunderstanding, or even misreading, of their work can certainly raise the blood pressure. My experience of the review process for $\mathrm{h}$-journals (which is more limited) is that the style is less 'bare-knuckled': in some cases the journal editor synthesises and combines the separate comments of two reviewers into a single commentary, and it is rather less common for there to be several rounds of reviewing and revision. There is a sense that at the first round of peer review, a decision is basically made either to publish or not, and the function of the reviewer feedback is then to make suggestions for improvement, development or clarification. As a consequence, there is less likely to be a sense of confrontation.

One particular problem with multiple-round reviewing, which Judith Becker alludes to, is the possibility that different problems, and requests for revision, are made at each stage. It is my understanding that most journal editorial policies try to prevent, or at least minimise, the likelihood of this happening (it is obviously very frustrating for an author to find that what seemed fine at round one is suddenly a problem at round two or three) by making sure that the same reviewers are used throughout the process, and that they do not suddenly raise new objections that could have been mentioned earlier. But there are perfectly benign reasons why it can happen: a new reviewer may be brought in if someone becomes unavailable, or the effect of one revision process may be to expose a problem or concern that was not apparent at the earlier stage.

Taking what Becker identifies as three categories of 'unaddressable critique', I think psychologists are open to the idea that emotional responses to music are due to more than just the 'specific structural aspects of the music' (category one), and equally, that various physiological measures are admissible as components of emotional responses to music. There is published work in s-journals (some of it referred to in Penman and Becker's paper) that demonstrates just those ideas. In both cases, it seems to me, the critical factor is how the case is made, in terms of both the strength of the empirical evidence and how 'accommodating' the model is that is presented. The third 'elephant in the room' factor (that reviewers are fundamentally suspicious of any investigation of religious ecstatics) is a worrying one. It would obviously be quite wrong to prevent publication of research simply on the basis of the category of 'human being' that it involved (as long as ethical considerations were properly met - as they seem to have been in this case), but I am not convinced of the evidence for this claim by Becker. I do not think that it is true that "if there is a taboo subject among psychologists and scientists in general, it is altered states". The quoted comment from one reviewer that "the problems of getting a genuine and solid experimental handle on the study of religious trance seem formidable" seems true to me; though of course not a reason to resist publication in that area, but rather the reverse. In short, I do not feel that these three categories of critique are unaddressable; though I agree that they are challenging.

Having read the two (s- and h-) versions of the paper, which differ only in minor respects (it would be interesting to know how an ethnomusicology journal would react, or has reacted, to the humanities version), I have come to my own view of the generous-spirited reflective remarks that Becker makes about the whole experience towards the end of her introductory essay. As a journal, Psychology of Music has, in my experience, adopted a very accommodating approach to the kinds of research that it will consider for publication, including plenty of non-statistical, even non-empirical, work. The phenomenology of individual musicians/listeners (mentioned as a commitment that ethnomusicology should not give up) is certainly not 
precluded in psychology of music research. Indeed, case study and other qualitative approaches have become increasingly accepted over the last 15 years. And while I certainly agree that ethnomusicology should not "give up its exploration of large issues that are resistant to empirical verification", neither should the psychology of music; there is plenty of work that does just that (theoretical, speculative, exploratory research).

To conclude, without (I hope) just seeming blandly or uncritically positive, my own view is that there are more opportunities for interdisciplinary work to find an outlet than there have ever been. There are more journals with interdisciplinary policies, and book publishers who are prepared to consider interdisciplinary proposals, as well as conferences and research centres with explicitly interdisciplinary aims. That does not eliminate the possibility of encountering the kind of frustrating experience that Judith Becker describes in her introductory essay. Indeed, it is important to be reminded of the different perspectives and expectations that may be involved, as well as the contribution made by institutional pressures tied up with funding and prestige (often very unequally distributed between the sciences and humanities) that I have mentioned in this commentary. But I think there are many reasons to feel extremely positive about the health of interdisciplinary research in general, and of the particular strength that it has within the study of music. In all kinds of ways, it seems to me that there are far fewer boundaries to cross than existed when I was a doctoral student 30 years ago.

\section{REFERENCES}

Duckles, V. et al. (2009) "Musicology." In Grove Music Online. Oxford Music Online, http://www.oxfordmusiconline.com/subscriber/article/grove/music/46710pg1 (accessed April 18, 2009).

Huron D. (1999) Lecture 3. Methodology: The New Empiricism: Systematic Musicology in a Postmodern Age http://musiccog.ohiostate.edu/Music220/Bloch.lectures/3.Methodology.html (accessed April 18, 2009).

RAE 01/2006 (O) (2006) RAE 2008 Panel criteria and working methods: Panel O. http://www.rae.ac.uk/pubs/2006/01/byuoa.asp?u=o (accessed April 18, 2009) 